\title{
On the Problems of the Informatization of the Principal Parts of Managing Agriculture in Hubei Province
}

\author{
Zheng Zhuang \\ Institute Economy, Yangtze University, Jingzhou City, Hubei Province, China \\ Email: enne12@sina.com
}

\begin{abstract}
China currently is still an agricultural country, and to develop the agricultural sector the most important part is peasants. However, at present in the process of informatization of new type principal parts of managing agriculture, there are many problems that are to be dealt with. Therefore, some better policies should be brought forward and the goal of better development of informatization of principal parts of managing agriculture could be realized.
\end{abstract}

Keywords- agricultural management, infromatization, problems, measures

\section{INTRODUCTION}

The main purpose of informatization of principal parts of managing modern agriculture is to make a big change from the traditional extensive type to modern intensive one so that the modern new type of agriculture in Hubei as well as the whole country`s agricultural sector can be developed healthily.

So far, despite the fact that the informatization is underway in Hubei province, yet there are many problems in that process, therefore, to put forward some effective policies and measures to deal with those problems to ensure the healthy development of our country`s modern agriculture is pretty necessary.

\section{II.THE PROBLEMS EXISTING IN THE PROCESS OF INFORMATIZATION IN HUBEI PROVINCE}

\section{A. The Circulation of the Arable Land is Problematic}

To further develop a new type of modern agriculture, the first task that government should do is the proper scale of agricultural production. Since the most important productive factor in the process of agricultural production is the arable land, only when the scale of agricultural production is up to certain standards can the modernization of agricultural production be realized. Therefore, in order to reach that goal, not only the effectiveness of the agricultural production should be raised, but also the capital which is used to expand the scale of production is a must. However, there is a premise people should consider seriously when they try to expand the scale of the arable land, and the premise is that the circulation of the arable land should meet no obstacles. As a matter of fact, this is not the case in reality. There are many reasons accounting for these problems. To begin with, many peasants do not want to put their arable land into circulation, for fear that if they do not have employment, they have nothing to meet their end, and the arable land remains the last hope that could save their lives. Even some peasants would do that, yet when they get nothing in return, they still could not vote for the circulation. Secondly, many places do not have laws and rules to regulate such circulation. When peasants agree to circulate their land or let someone undertake their land, they will not report this case to governmental agencies, hence, no one knows or makes a record of what they have done to their land. Even though peasants could sign the contract with the contractors, the contents of it are not clear enough, and in some cases, are not reasonable. All these unfavorable factors would be harmful to the arable land management. Thirdly, a great amount of the arable land that people get from the circulation usually does not meet the need of the development of modern agriculture.

\section{B. The Supports from the Government are not Effective}

First of all, many documents released from the government are informal, idealized, and impractical, and worse still, the numbers of co-operatives are also limited. For example, in Xinagyang city, there are 635 economic cooperatives which received less than 5 percent of government support. Secondly, there is a common sense in the rural areas that the cost of hiring employees and using electricity is really high, and this is the serious problem that remains to be tackled. Thirdly, the shortage of infrastructure construction is in rural areas. Due to this shortage, some diseases and insect attacks as well as floods and droughts cannot be guarded against effectively. Fourthly, the lack of technologists who master in some fundamental skills. And because the government does not implement some favorable policies which could attract young technologists to join the cooperatives, therefore, the situation for the development of cooperative is not optimistic.

\section{The Low Ability of the Managing Stuff in the Cooperatives}

In general, the managing staff of the cooperatives does not have educational background, and even they have, it is only confined to the high school education. Take Xiantao city as an example. Of those legal representatives in the cooperatives, only 12 percent has received high school education, and the rest either middle school education or even are illiterate. And the people who could both know how to run and manage the cooperatives and know how to market are extremely rare, therefore, since many staff in the cooperatives cannot figure out the better ways to run the organization, and the organization could not play its role in 
pushing forward the development of modern agriculture in this sense, the road to realize the goal of new modern agriculture that lies before the people will be full of turns and twists. Besides, some leaders in the cooperatives are not open-minded, and do not have the sense of team-work, and when there comes the risks caused by the fluctuations of market, they fail to make an agreement and take immediate actions to reduce the damages. Another reason for the low ability of the managing staff is that the young people especially with some key technologies would not come to the organization in rural areas, for the people they have to meet are older than them. And this reason could be seen as the one of the causes to the shortage of talents in the cooperatives.

\section{The Ineffective Management of the Cooperatives}

Although some cooperatives have already made some regulations and set up the boards of directors and the boards of supervisors, while the duties that are assigned to people are not clear, there are no strict rules placing in running and managing cooperatives at all. For example, some managers paid too much attention to the establishment of the system, ignoring the feasibility of the rules. And some people, who do not have their own production base, in the cooperative overemphasize the sale sector, and the production sector is neglected. While others with their own base tend to divide the sale sector and production sector, and in their minds, the cooperatives should only be served as the intermediary. What's more, the members of the cooperatives usually could not form an agreement on how to manage the cooperatives, therefore, many cooperatives fix their attention to the money they could earn rather than the service they should provide. All these defects could contribute to their failure in enhancing the competitiveness of their cooperatives. For instance, currently, in Xiangyang city, about 4 percent of cooperatives has set up the financial management system, about 20 percent has set up the control mechanism, while only about 5 percent has their own democracy system.

\section{THE MEASURES TO THE PROBLEMS OF THE INFORMATIZATION}

\section{A. Improving the Now-Day Arable Land Circulation}

First of all, government should establish a better platform on which the arable land could be circulated plainly, and then set up a scientific and proper system of arable land circulation, and the proper process of the circulation is also very necessary. What they should do is to strengthen the effectiveness of the supervision of land circulation contract so that the effective circulation could be realized. Secondly, to establish and complete the market which could offer favorable and fair environment under which signing the land contract would be under supervisions from governments. Governments should also set up the proper mechanism for the marketization of circulation and the market-set prices mechanism should be established so that could be conducive to development of modern agriculture. The mechanism could make government know better the prices of the arable land in the market, and the benefits of peasants could be safely protected. Finally, governments should introduce the land joint-stock partnership, and in this way peasants could become the shareholders of the cooperatives, and it will be really good for the agricultural production and sale. And in the end, the cooperatives should also combine stretches of the land, changing the ways of peasants holding the land contract personally.

\section{B. Increasing the Governmental Support in the Principal Parts of the Modern Agriculture}

First of all, the documents about the principal parts of modern agriculture released by the government must be implemented so that the favorable environment for the further development of principal parts could be formed. Secondly, the government should support and bring up new principal parts. Besides, when government wants to support the cooperatives, the local reality should also be considered in that only in that case can the policies be made full use of. Speaking of governments, the most important things they should do is to provide financial support and loans assurance to those well functioned rural cooperatives and the large projects and at the same time encourage enterprises to work with cooperatives for the purpose of management and development of modern agriculture. While for the people in the rural areas they could pay more attention to the social capital, if the government support is limited, and they also should adopt the functions of the market so as to back up the healthy development of cooperatives which guarantees more loans for the principal parts. And besides, the governments should also expand the scale of assurance, hence, the problems of financial resources and the high cost of electricity will be properly handled. In the end, government should also put great effort to construct the infromatization of principal parts of modern agriculture and raise the awareness of the importance of service for the principal parts.

\section{Introducing and Training Talents and Improving Current Regulations}

To begin with, the cooperatives should set up a higher standard to get more talents trained, thus, they could contribute their knowledge to development of modern agriculture and they could improve their skills and abilities to better run and manage these cooperatives. What s more, the cooperatives should also introduce and foster the new financial staff and in this way the levels of financial management will be improved significantly. This could also meet the demands of the market. Secondly, people in these cooperatives should constantly improve and complete the existing rules and orders and introduce the mechanism of mutual supervision, democracy, and joint management. Thirdly, people should make the duties which some people hold responsible clear. Finally, people should build up the security system which could guarantees that the arable land of rural areas should be managed properly and lawfully. Also, they should change their idea of only relying on the land to make money. When people could change their mind, and the security system would be placed, then the goal of developing the modern agriculture can be reached. Another thing that these people have to do is that they should put together the fees from peasants, collective subsidies and government auspices, and encourage peasants to positively circulate their arable land on the rational, formal and 
volunteer base for the purpose of satisfying the need of development of modern culture.

\section{Emphasizing on the Leading Role of Principal Parts of the New Parts of Managing Modern Agriculture}

Firstly, the government should focus on some large-scale enterprises which could do business with agriculture and thus could push forward the development of modern culture. Therefore, governments should encourage these enterprises to develop the secondary industry on the base of there being a need from the modern agriculture. For instance, they could develop aquatic feeding or further processing of biological products and so on. And the secondary industry could include storage, sale, and service. Besides, government should entice the big companies into working with some scientific institutions and through this way, some important technologies could be put into practice quickly and thus quicken the pace of development of modern agriculture. Secondly, government should develop the interests-bind mechanism through which government could put more supports in such fields as the construction of projects, and later-on operations of these projects. As the price of the agricultural products would fluctuate in accordance to the demands of the market, governments should provide some help or monetary policies to ease the hit from the fluctuation. With the help from the government, the enterprises would like to make cooperation with the rural cooperatives, and they also could more confident when the crisis comes. Therefore, to establish a long-time, steady, and close interests-bind mechanism with enterprises is pretty necessary.

\section{CONCLUSION}

Although China has already made a progress in autonomous management of agriculture, many provinces still have to face a lot of problems during the process of developing modern agriculture, for example, in Hubei province. Therefore, governments should take actions to handle these problems, and only when these problems are solved can the new type modern agriculture develop smoothly.

\section{REFERENCES}

[1] Liang Yu. The current situations of the modern agriculture with some advice from policies--in the case of Hubei province[J]rural economy and technology, 2015, (2): 22-23.

[2] Wang Yuanfa. The comparison of the principal parts of the modern agriculture between China and foreign countries with some advice from policies [J] problems of rural economy, 2014, 35(10): 26-32.

[3] Zhou Tian, the current situation of the new modern agriculture with measures [J]. Hubei rural science, 2014, 53(16):3952-3955. 